\title{
Accident and Emergency Medicine
}

\author{
Lt Col TJ Hodgetts \\ FRCP,FFAEM,Dip IMC RCSEd,DipMedEd,RAMC \\ Specialty Adviser in A\&E Medicine \\ Professor of Emergency Medicine and Trauma
}

\author{
MDHU Frimley Park Hospital, Portsmouth Road, Frimley, Surrey GU16 5UJ \\ Email:tim.hodgetts@virgin.net
}

\section{Introduction}

Accident and Emergency (A\&E) medicine is the most rapidly developing specialty in the Defence Medical Services. A recognised training pathway was established in 1990 and the first consultant appointed in 1994. The specialty currently has 3 consultants, 4 specialist registrars, and 9 basic professional trainees (training or accepted for training). There are a further 8 medical officers completing general duties who desire a basic professional training in the specialty. ${ }^{1}$

So why are so many military doctors choosing to train for a career in A\&E Medicine? The national profile of the specialty has raised in recent years through the establishment of recognised higher professional training programs, the institution of entrance (MRCSEd(A\&E), see below) and exit (FFAEM, see below) examinations, and the inauguration of the Faculty of Accident and Emergency Medicine as a parent body. The value of this specialty in an operational setting is obvious to emergency physicians, but military doctrine has lagged in recognising the core role that the specialty now plays in civilian practice. This has been rectified and the current operational establishment provides a realistic compliment of specialists in this field.

A possible factor in the popularity of the specialty that cannot be ignored is that it fits the personal profile of many doctors who join the Services. It is seen as exciting and with constant challenges. This of course is true, but to avoid disappointment it should be balanced with the routine (there are many more sprained ankles than there are polytrauma cases) and not over-glamourised.

\section{The first step}

Medical cadets and pre-registration house officers have the opportunity to register for a senior house officer (SHO) post in A\&E Medicine prior to their basic military training on the New Entry Officers' Course. This provides invaluable practical experience and critical decision making abilities before embarking on general duties, which are often undertaken without immediate access to peer support.

The present structure only facilitates such a job immediately post-registration. Support is not available for an A\&E SHO job following the New Entry Officers' Course, but prior to general duties. There is a strong argument for recommending an A\&E SHO job for all doctors prior to general duties. This has been the subject of much discussion, although there is no directive yet to adopt this change. The availability of these jobs remains limited, and early application is recommended.

\section{Career tip}

If you want an SHO A\&E post prior to your general duties, register your application (Army) with: Medical Officer Recruiting, Regimental Headquarters RAMC, Keogh Barracks, Ash Vale, Aldershot, HAMPSHIRE GU12 5RQ. Telephone: 01252340309

\section{Basic professional training}

All hospital specialists require a period of basic professional training. Most specialities require the individual to obtain a higher diploma within this period, as the milestone to allow entry into higher professional training.

The specialty of A\&E medicine has worked hard to enhance its professional image. For some years it was regarded as the province of the failed orthopaedic surgeon, and some may uncharitably persist in this view. This situation has not been helped by the lack of a basic professional training program specific for the specialty, relying instead on Fellowship of a Royal College of Surgeons or Anaesthetists, or Membership of a Royal College of Physicians as the entry criteria for specialist registrar training. If you want to be a surgeon, you would not train as a physician first - so why is it necessary to follow another career pathway before being allowed to train in A\&E?

The Royal College of Surgeons of Edinburgh had the vision to introduce an entry qualification for higher training in $\mathrm{A} \& \mathrm{E}$ Medicine, the MRCSEd(A\&E). All military basic professional trainees in A\&E Medicine are recommended to take this examination. This does not, however, close the door on trainees who wish to change specialty following or during BPT in another specialty. The MRCSEd(A\&E) clinical examination requires a minimum of one year A\&E Medicine at SHO level, one year of surgery (house job counts) and one year of medicine (house job counts). There is no Part1/Part A to this examination, and it is necessary to obtain MRCP Part 1 or MRCS Part A.

\section{Career tips}

If you want a basic professional training in A\&E Medicine do the following:

1. Inform the Specialty Adviser in $\mathrm{A} \& \mathrm{E}$ in writing. You may do this as a cadet, a house officer, or a general duties medical officer - but the sooner the better.

2. Inform the Postgraduate Medical Dean in writing of your career intentions (Royal Defence Medical College, Fort Blockhouse, Gosport, Hampshire PO12 2AB. Tel: 01705 765671). Your application will be considered by the Royal Defence Medical College Council.

3. Inform your single service appointing officer, ideally in writing, as this will help identify an available rotation (ARMY: Army Personnel Centre, AMS MCM Div, Kentigern House, 65 Brown Street, Glasgow G2 8EX. Tel: 01412243432 ).

4. If you are already embarked on training and are changing specialty, complete an application for change of specialty available through DPMD's office.

5. Use your time wisely as a GDMO to prepare for (and possibly sit) MRCP Part 1 or MRCS Part A. 


\section{Higher professional training}

This is a 5-year program identical to the Calman program that your civilian counterparts will undertake. Individual programs are designed by the Specialty Adviser in A\&E Medicine and approved by the Defence Postgraduate Medical Dean (DPMD), prior to approval by the Specialists Appointment Committee (SAC).

After you have obtained your higher diploma you may apply to DPMD for approval to train as a specialist registrar. This will involve a commitment to extend your length of service, which should be processed through your commanding officer. If you are accepted for training (and this is principally dependent upon available training positions to support established service consultant posts) then you will attend a regional appointments committee. These committees are civilian, with representative military officers in attendance (DPMD, Specialty Adviser A\&E). The objective is simply to demonstrate you have achieved the same milestones as your civilian counterparts. Subsequently, you are recognised as a Specialist Registrar $(\mathrm{SpR})$ and are issued an individual National Training Number (NTN).

During the five years of training are a series of secondments that will include anaesthetics, intensive care, coronary care, paediatric accident and emergency, and specialist surgical disciplines (ophthalmology, burns and plastics, neurosurgery, cardiothoracic surgery, ENT). Annual training objectives are set by the Specialty Adviser A\&E, and are reviewed every 6 months. You will attend a formal assessment committee every year within the region you are training. Early in the program all specialist registrars will complete the appropriate modular courses if these have not already been obtained (ATLS, ALS, APLS, MIMMS). Instructor status is encouraged as regular involvement in teaching ensures the individual remains current and confident within these critical areas. There are opportunities for higher education if this is desired, which will be outside the 5-year program (invariably implying an extra year within the training program), and the desire to undertake an M.Sc, MD or M.Phil will be strongly supported. Publication is encouraged and there are a wealth of opportunities for audit and research.

The value of exposure to another system of developed emergency care is recognised, and applications for a secondment in the final year of training to a centre of excellence abroad will be supported. This is dependent on approval by DPMD. You will also be required to sit the Fellowship of the Faculty of A\&E Medicine (FFAEM) exit examination during your final year, or shortly afterwards. A certificate of completion of specialist training (CCST) can be issued without this examination for individuals to be included on the Specialist Register, but a consultant appointment committee would have a dim view of any candidate who did not hold the qualification (should you leave the Services and apply for a job, that is!).

A substantive consultant post in the Defence Medical Services is awarded on successful completion of an Armed Services Consultant Approval Board (ASCAB). This is a potentially daunting combination of the President of the Royal College of Physicians and senior members of the Faculty of A\&E Medicine, together with DPMD and the Specialty Adviser. However, this should not be regarded as too daunting as our trainees are provided with the highest standard of training and would not be put forward for approval of consultant status if there was not a high confidence of success.

\section{Career tips}

1. Enjoy yourself - you will never have so much freedom as when you are a specialist registrar!

2. Develop one or more special interests (for example, prehospital care, major incidents, mass gathering medicine, sports injuries, paediatric A\&E, remote medicine, telemedicine, severe trauma, education) as these will compliment the interests of existing consultants: you can be good at everything, but great at only one or two things!

3. Once you have been awarded a National Training Number, you must enrol with the JCHT(A\&E) office based in the Faculty of A\&E Medicine who have offices at the Royal College of Surgeons of England (Tel: 0171 405 7071).

4. Join the British Association for Accident and Emergency Medicine. This will provide you with the Journal of Accident and Emergency Medicine, and membership of the A\&E Trainees' Association which holds regular regional meetings.

\section{Operational role}

Trainees are often concerned about operational deployments that will interfere with and delay their professional training. Basic professional trainees (ARMY) may be required to act in a 'general duties medical officer' capacity within a role 3 field hospital. Higher professional trainees are protected to a great extent from operational duties, and can expect not to be nominated except in extreme circumstances (large scale deployment of an OOTW or War).

The specialty has struggled with ensuring an operational identity for OOTW, largely as a result of the small numbers of personnel. The first operational deployment of a consultant A\&E Medicine was in 1999 in support of a 50-bed role 3 field hospital with two surgical teams (OP AGRICOLA, Kosovo).

\section{Consultant responsibilities and opportunities}

A consultant's first responsibility is to ensure that he/she is adequately prepared for their clinical role in OOTW or War. The development of Ministry of Defence Hospital Units has provided the chance to work in busy district general hospital A\&E departments, with exposure to the broad spectrum of emergency medicine. Many departments now have two or more consultants, but on-call commitments are heavier than other specialties (range 1:2 to 1:4 on average, all with prospective cover!).

Consultants can expect to share in the clinical and administrative management of these large departments, and will have responsibility for specific functions such as department audit, major incident planning, major trauma management, pre-hospital care liaison, complaints procedures, and SHO training. It would be expected with time that the role of Clinical Director would rotate through the military consultant(s) in a department.

There is a high educational component to emergency medicine. Most consultants will have the opportunity to instruct on one or more of the national modular training programs (ATLS, ALS, APLS, PALS, PHPLS, PHTLS, MIMMS, Generic Instructor) and will be involved with organising these courses locally. There is a continuing need to support such courses within the DMS (BATLS, ALS, MIMMS).

All the existing consultants in the DMS have developed national (and in some cases international) profiles while still in 
higher professional training, and continue to build on these. Opportunities for publication, research, and audit are vast for our trainees. If, on the other hand, you aspire to a large supplementary income, then you should turn your attention elsewhere!

\section{Career opportunities}

1. Maintenance and development of clinical skills within a busy district general hospital.

2. Opportunities for academic enhancement and academic affiliation.

3. Research and audit (grants have been successful to support clinical effectiveness and research projects within the military clinical environment, and outcomes have set national standards).

4. Regular involvement with national (and international) medical training initiatives for both military and civilian personnel.

5. Support to develop your own sphere of interest and profile within the field of emergency medicine.

6. Publication (existing consultants have extensive involvement in publication of articles, books, and editorship of peer-reviewed journals).

\section{The future}

The considerable expansion of our consultant cadre will pose an intellectual problem in determining the best place for all consultants to practice. To outline the possibilities would only represent conjecture, but quality clinical activity and maintenance of military ethos would both be paramount in any solution. The new Centre for Defence Medicine will offer positions, and there would be likely expansion within the MDHU's to provide the short and mid-term solution.

Following appointment as a consultant there is a minimum of three years return of service. This has been a watershed for our first two consultants in the specialty subsequently leaving the DMS. I strongly believe that the opportunities for personal development in this specialty are currently greater in the DMS than in the NHS. When coupled with the enhanced ability to influence change compared with the NHS, and a growing cadre of enthusiastic, high calibre trainees it is anticipated that officers will be encouraged to continue their service.

Accident and Emergency Medicine has arrived in the DMS. It is a rapidly developing specialty that reflects best standards of practice in the NHS - and in a number of cases is involved in setting national standards. But the most important factor to sustain the growth of the specialty is the high calibre trainee. It could be the career for you. 